\title{
Problem-Based Learning for Responsive and Transformative Teacher Professional Development
}

\author{
Tom J. McConnell, ${ }^{1}$ Joyce M. Parker ${ }^{2}$ and Jan Eberhardt ${ }^{3}$
}

Abstract
Educational reform should include teacher professional development (PD) to help educators learn how to
implement new programs. This article shares a research-tested model of PD that uses the analytic framework
of Problem-Based Learning (PBL) to support professional learning. Evidence suggests that PBL is effective in
changing content knowledge and pedagogical practice. To teach content, facilitators engage teachers in learning
activities designed using common PBL structures. Stories about authentic phenomena present problems asso-
ciated with specific concepts. Learners work in groups to analyze problems, seek additional information, and
construct plausible solutions. This same approach can support Professional Learning Communities (PLCs) to
help teachers examine and revise their own teaching. In this model, teachers collaborate to identify "problems
of teaching." The group uses PBL to analyze information and solutions. Teachers research teaching strategies,
test a proposed strategy, and analyze evidence to build new understandings of teaching.
Keywords: Teacher PD, Problem-Based Learning, Professional Learning Community, Action Research

As we think about the need to create models for transformative education, education leaders need to consider how teachers will be educated in whatever new programs we develop and implement. If we truly value transformative teaching strategies, we should also think about how to best provide professional development (PD) for teachers that is as transformative as we aim to create for students. This paper presents NSF-funded research about effective PD that employs Problem-Based Learning as a pedagogical strategy. The model was developed and tested with $\mathrm{K}-12$ teachers over a four-year project.

Professional development is an important element of any education system. Any professional, including teachers, enters the workplace as a novice, so continued learning is necessary. Changes in student needs, diversity, new technology, revised standards and new curriculum, and many other variables also create a need for continued learning for even the most experienced teachers. But especially as we explore ways to

Full listing of authors and contacts can be found at the end of this article. identify and adopt new strategies that create a more transformative education system, teacher PD needs to be an intentional and well-planned component of any reform.

For the PD planner, this presents a challenge very similar to those facing the teachers we serve. Teachers who participate in any professional development (PD) program are sure to be a diverse group of individuals. Some enter the program with years of teaching experience while others are new teachers. Participants may come together from different disciplines, grade levels, school cultures, and communities. They also have different educational backgrounds and probably very different personal experiences in their own lives. One of the key challenges in planning effective PD is ensuring that all participants benefit.

But in any discussion of "transformative education," we must also think about how to help this diverse array of teachers learn to implement educational strategies in a way that empowers them to address problems in their own particular settings. If we wish to develop a

Published by the Global Insitutute of Transformative Education (http://www.gite.education)

(c) McConnell, Eberhard, \& Parker. 2019 Open Access This article is distributed under the terms of the Creative Commons Attribution NonCommercial NonDerivative 4.0 International License (http://creativecommons.org/licenses/by-nc-nd/4.0/), which permits unrestricted use, distribution, and reproduction without revision in any non-commercial medium, provided you give appropriate credit to the original author(s) and the source, provide a link to the Creative Commons license, 
body of students that has the capacity to face new problems in a culturally relevant way as they develop critical thinking and problem-solving schools that lead to innovation and meaningful change, we should also apply the same goals to the ways we teach teachers. The design of the PD program also needs to be one that not only permits but encourages teachers' leadership in identifying, investigating and implementing changes in curriculum, in classroom practices, and pedagogical strategies (Yaron 2017).

\section{The PBL Project for Teachers}

The Problem-Based Learning Project for Teachers was an NSF-funded research project that developed a comprehensive PD program for science teachers in grades K-12. Participants enrolled in the program were asked to identify content standards for which they felt they needed to improve their teaching. Planners designed content learning activities to be offered in the first part of a summer workshop. The content of the activities was based on teachers' selection of content topics or strands. In the second part the summer workshop, teachers learned to apply PBL to teaching practice, and formed Professional Learning Communities ((PLCs; Hord 1997) that would meet in the next school year. The PLC groups then met monthly to facilitate a PBL-based inquiry into problems of teaching practice each participant had identified. This PBL inquiry process resulted in lasting and meaningful changes to the way participants presented content, assessed student learning, managed classroom behavior, or designed entire curricula.

The information shared in this paper reflects the research conducted over four years of the project, as well as continued refinement of the model through continued practice and reflection by the author and other principles in the PBL Project for Teachers. While the reader will find mention of content learning, most of the discussion will focus on using PBL to examine pedagogy.

\section{Problem-Based Learning}

Problem-Based Learning was first developed in the field of medical education as a response to a need to improve students' ability to diagnose illnesses in a clinical setting (Barrows 1980). Instructors had noticed that first-year medical students were very good at memorizing facts, but they were not very successful in translating that knowledge to the type of clinical practice they face in diagnosing the condition of real patients in authentic situations. This is largely because the patients do not often present as cases that neatly fit the textbook examples. Patients sometimes presented information that was not directly relevant or failed to show symptoms that would help in the diagnosis.

PBL model developed for medical schools has since been adopted in other content areas (Hung, Jonassen, and Liu 2008) in which students need to learn critical thinking skills that resemble clinical practice in a medical setting. One of these areas is education.

Teachers may be thought of as clinicians. Like a physician, a teacher must apply the critical thinking skills of diagnosing a problem and developing an action plan to address a need. Each day, teachers assess students' actions and ideas, make judgements about what ideas students are developing or have constructed, and devise strategies for helping students achieve the objectives not yet mastered. For nearly two decades initiatives to improve the quality of teaching have pointed to the clinical practice view of teaching as a structure for teacher education and professional development. The Carnegie Corporation of New York helped shape teacher education through a clinical practice model (CCNY, 2001), and the latest CAEP standards for accreditation of teacher preparation programs (Council for Accreditation of Education Preparation 2013) call for clinical practice as a part of teacher education in the United States based on studies from the preceding accreditation organization (Zimpher et al 2010). In both of these initiatives, teachers need to learn to think like master teachers, just as medical students need to learn to think like doctors. Those skills require both content knowledge and an understanding of pedagogical approaches that meet the needs of diverse students.

The model included in this paper is described in more detail in a book to be published in 2020, Problem-Based Learning for Responsive and Transformative Teacher Professional Development (McConnell, Parker, \& Eberhardt, in preparation) as part of the Problem-Based Learning for the Science Classroom series (McConnell, Parker, \& Eberhardt, 2016-2018) of books from National Science Teachers Association Press.

\section{PBL Problem Structure}

Problem-Based Learning features a real-world problem presented in the form of a story divided into two pages. The problem in the story is authentic in that it needs to be either a real event or a fictional one that reflects real phenomena. The problem story is also ill-defined - readers are not given all the facts needed 
to solve the problem and may be given information that is not needed to solve the problem. This messy nature of the problem helps learners to think about what information is relevant and identify information they need to find from other sources. This feature of the problem more closely resembles the real world than traditional textbook story problems in which students need all the given information, and nothing more.

Learners in a PBL lesson then use an analytical framework to facilitate a collaborative discussion that helps learners identify known and unknown information, and begin proposing hypotheses, the possible solutions they think may help answer the challenge presented in the problem. A graphical representation of this process can be seen in Figure 1.

Learners begin by reading Page 1 of the story, then generate a list of three main types of information:

- What do we know?

- What do we need to know?

- Hypotheses.

A facilitator (the teacher) helps monitor the discussion and record ideas on the whiteboard or papers posted where the class can see them. When the class has exhausted their analysis of Page 1, the facilitator gives the learners Page 2, and the process is repeated. After analyzing Page 2, the class identifies the "What do we need to know?" items they feel are most relevant as "learning issues." They then search for more information from the internet, library, textbooks, and other resources provided by the facilitator or through investigations. At the end of the discussion, students or groups present their findings and propose a solution to the problem. Students are expected to use evidence to support their proposals. The discussion of alternative solutions may lead to selection of a final solution for the problem, or students may be asked to write about the solution they feel is best.

In the PBL Project for Teachers, this structure was used to help participants learn about the science content standards they had identified when they enrolled in the program. The PBL Problems created by project planners were the basis of problems included in the first three volumes of the PBL in the Science Classroom series.

Research on teachers' learning with these content PBL problems revealed that about $83 \%$ of teachers gained significant amounts of content knowledge during the activity, including knowledge that persisted
Figure 1: PBL Analysis Framework. (From McConnell, Parker, \& Eberhardt 2016, p. 4)

\section{The PBL Process}

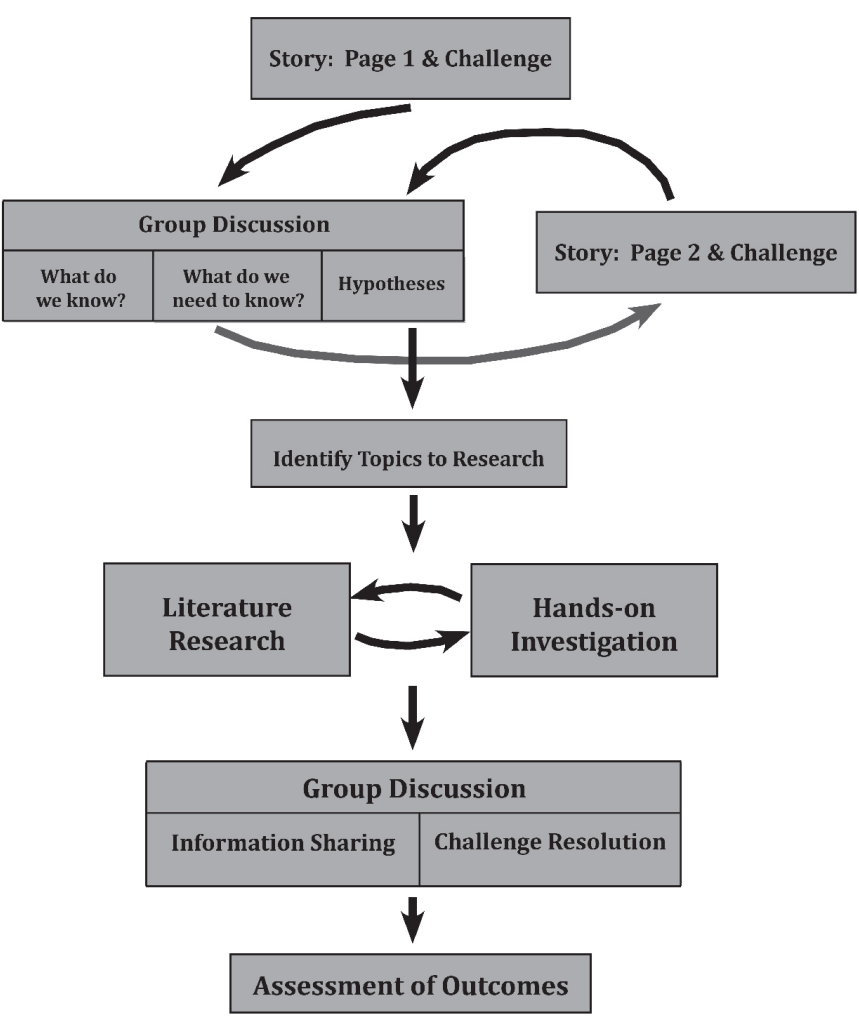

for at least 8 months (McConnell, Parker \& Eberhardt 2013). The data revealed that teachers with varying degrees of prior education and content knowledge were all able to gain new ideas about the science topics through the PBL lessons.

Our research also suggested several key elements in designing effective PBL-based professional development for content learning. In order to be most effective, teacher PD programs need to include...

- Teacher participation selection of content topic

- A close link between content taught and standards (or curriculum)

- A mix of text-based and hands-on activities to support learning

- Time for individual teachers to process ideas

- Multiple forms of assessment of teachers' understanding, with an emphasis on openresponse items 


\section{Applying the PBL Structure to Pedagogical Learning}

Designing PBL professional development activities for content learning is very similar to writing lesson plans for K-12 students. The structure of the lesson and the way it is facilitated are nearly the same. But if we apply the structure of PBL to professional learning about teaching practice, the structure needs to change in several ways. The following section describes the design of a "Focus on Practice" component of the PBL Project for Teachers.

The structure of a PBL problem for the "Focus on Practice" (FoP) is very different from a content problem. One key difference is that the central focus of the problem is identified by the participant, not the facilitator. Each teacher developed a unique problem that was very specific to his or her personal teaching situation. The problems were also resolved over the course of at least two months during the formal presentation of the teacher's research into the "problem of practice." In some cases, teachers spend most of the school year examining their question and trying various solutions. The extended time frame is very different from most content PBL lessons. Figure 2 provides a comparison of the two different structures for a PBL problem.

Another change was the source of information upon which the group builds a solution to each problem. When applied to pedagogy, teachers were encouraged to use text-based resources, but they were also

Figure 2: Comparison of PBL Structure

\begin{tabular}{|c|c|}
\hline Content PBL Problems & FoP PBL Problems \\
\hline \multirow{2}{*}{$\begin{array}{c}\text { Page } 1 \text { - The Story } \\
\text { (Generated } \\
\text { by facilitator) }\end{array}$} & $\begin{array}{l}\text { Page 1- Problem of Practice } \\
\text { (Generated by teacher) }\end{array}$ \\
\hline & $\begin{array}{c}\text { Teacher collects evidence from } \\
\text { practice, presents to group }\end{array}$ \\
\hline Group PBL Analysis & Group PBL Analysis \\
\hline $\begin{array}{l}\text { Page } 2 \text { - More Information } \\
\text { Generated by facilitator }\end{array}$ & Page 2 - Proposed Solutions \\
\hline Group PBL Analysis & \multirow{3}{*}{$\begin{array}{c}\text { Teacher and FOP group } \\
\text { research and test } \\
\text { possible solutions }\end{array}$} \\
\hline Search for more information & \\
\hline Construct solutions & \\
\hline Group discussion of solutions & $\begin{array}{l}\text { FoP Group discussion } \\
\text { of solutions }\end{array}$ \\
\hline
\end{tabular}

asked to collect evidence from their own classroom. This evidence included samples of student work, the teachers' reflective journal, and videotaped records of a lesson when possible.

The roles of group members also shifted. Each teacher had primary responsibility for collecting information (research and evidence from the classroom). An initial analysis of that data was done individually by the "owner" of the problem before the evidence was brought to the group to be shared. Group members then helped analyze the evidence, but most of the responsibility for a final solution fell on the problem's owner.

The "Focus on Practice" (FoP) was the final part of the summer workshop and focused on pedagogy. PD planners led sessions on how to use PBL as a way to structure teacher-led inquiry and reflective practice within the context of a Professional Learning Community (Hord 1997). The summer session included sample PLC meetings to model the process we encouraged teachers to employ for the following school year. Teachers also formed their new PLCs and began developing a schedule for a meeting each month through the school year. Those groups met to discuss potential teaching problems that would guide each participants' inquiry. Other workshops included practice in videotaping their own classroom and the process of analyzing videos of teaching practice.

The PLC groups were first created by facilitators to generate groups with similar grade bands (Grades 6-8 or 3-6 for example), geographic location to help facilitate meetings, or common subject areas (Earth science, physical science). The ideal group had some similarities, but we also found some value for including a more heterogeneous group. Teachers sometimes negotiated different groupings, usually based on geographic location when a teacher lived closer to one group but taught closer to a different group.

To help teachers focus on a problem of practice they could use as their PBL problem, teachers were asked to write a "Day in the Life" journal entry. This writing asks the teacher to write about a typical day in their classroom that reflects a problem they wish to resolve or improve. The problems could focus on a science concept they struggled to explain accurately, a classroom management issue, or a particular lesson that does not seem to be effective in achieving the learning goals. In a sense, the "Day in the Life" writing served as Page 1 of that teachers' problem.

Just as in a content problem, the next step was group analysis. Teachers shared their "Day in the Life" writings 
with members of their PLC and discussed what they knew or needed to know about the problem. Groups used the same three-topic lists as in the earlier example:

"What do we know?"

"What do we need to know?"

"Hypotheses."

A "hypothesis" in this case was a possible strategy to test out in the classroom. In some cases, group members would send the problem's owner a book or journal article that might support or explain the proposed solution. Figure 3 lists some samples of the problems of practice generated by participating teachers, along with the hypotheses they developed to be tested during the academic year.

This "Page 1" analysis took place during the summer workshop. Each member shared the ideas they generated for a problem and talked about possible solutions. Teachers then planned when in the school year they would test their solutions and schedule meetings to be led by each member of the group. Each teacher was expected to teach the at least one lesson in which they would test their proposed solution before the assigned meeting. Some participants extended their research to span an entire unit or most of the school year. Teachers selected a one-month period that would be the focus of the problems they presented to the FoP group. Teachers shared entries from a reflective journal written before and after the lesson, collected at least three samples of student work showing a range of achievement, and recorded a videotape of the lesson. That teacher was also expected to view the video and select a segment of about 10 minutes that represents the problem being examined. Each meeting was mon-

Figure 3: Sample hypotheses about problems of practice

\begin{tabular}{|l|l|}
\hline Problem of Practice & Hypothesis \\
\hline $\begin{array}{l}\text { Implementing my new } \\
\text { chemistry unit which } \\
\text { is not related to other } \\
\text { topics I am required } \\
\text { to teach. }\end{array}$ & $\begin{array}{l}\text { If I use observing and careers as themes } \\
\text { students will become better observers } \\
\text { and more aware of reasonable careers, } \\
\text { because we will be able to work on these } \\
\text { isdeas througout the school year in } \\
\text { multiple contexts. }\end{array}$ \\
$\begin{array}{l}\text { My students are } \\
\text { poor writers who vague language } \\
\text { and give incomplete } \\
\text { explanations. }\end{array}$ & $\begin{array}{l}\text { If I require an explicit structure when } \\
\text { students write explanations and have } \\
\text { them practice editing their own and } \\
\text { writing will become more precise and } \\
\text { complete because they will internalize } \\
\text { the structure through extensive practice. }\end{array}$ \\
\hline
\end{tabular}

itored and led by a facilitator, usually one of the PD program planners.

When each teacher's assigned month to present arrived, the group would listen to a summary of the problem and a review of the lesson taught. They also viewed the videotape and samples of student work.

During this discussion, the group commented only on observations they made during the video. Teachers were reminded not to make inferences or judgements or to propose solutions as they watched. This is similar to helping learners in a content problem to focus on "What do we know." Their observations were recorded on the "What do we know?" list in accordance with the PBL process. This process parallels the Page 2 analysis shown in Figure 1. There are also elements of the research phase of the PBL structure in that teachers were "investigating" and collecting evidence from the lesson they observed.

After viewing the video, the group shared questions they had about the video and student samples. The questions generated are part of the "What do we need to know?" list during the analysis process. Some of the questions may be answered by the teacher presenting the video and might focus on questions about the context of the lesson such as previous lessons, plans for the next day, or the teacher's directions for the students. When the questioning step is done, the group can begin generating a list of solutions. This may focus more on drawing conclusions about the strategy tested by the teacher presenting the problem, or it may lead to new suggested strategies. The conclusion of this presentation comes when the teacher has feedback from the

group that can be useful in shaping pedagogical choices for future classes. If the meeting led to a list of topics the teacher wanted to by the teacher presenting the problem, or it may lead to new suggested strategies.

The conclusion of this presentation comes when the teacher has feedback from the group that can be useful in shaping pedagogical choices for future classes. If the group created a list of topics for further research or classroom trials, the presenter would use then the next month as an opportunity for further research. In some cases, more questions arise, or the teacher may wish to test another solution, either alone or with help from the group. 
The process is flexible enough to permit multiple iterations of the cycle of reflective practice represented in the PLC's process. This would be followed by another discussion in the next PLC meeting to share what the teacher found. This presentation was usually more informal and briefer but gives a chance for the group to extend their learning beyond the initial month.

Teachers who participated in the PLC groups to analyze their own problem of practice were invited to attend a year-end meeting to share their work and celebrate each other's successes. Before the year-end meeting was convened, participants were asked to communicate their inquiry in a formal written summary. The document included the original problem statement and hypothesis, a description of the lesson or unit in which the hypothesis was tested, and a review of the evidence shared with the teacher's PLC. The summary also included a final "solution" statement and a reflection on what the teacher learned in the process. Some of the teachers chose to also write about a "next problem" they would investigate.

The process led to changes not only in the way participants taught the lesson they identified, but the changes transferred into many other aspects of the teachers' practice. Many of the teachers reported sharing the process with other teachers in their buildings and adopting the model for their school's improvement plan. Teachers' lesson plans developed during the workshops also reflected changing ideas that suggest meaningful learning. The researchers also reviewed evidence of effective PBL implementation in PLC groups and developed recommendations for PD planners:

- PLCs function best when teachers feel a sense of belonging and ownership of the group.

- PLCs are most effective when teachers lead by identifying problems of importance to them.

- Analysis and discussion must focus on teaching practice, not the teacher.

- Shared leadership leads to a sense of accountability to peers - a strong motivator.

\section{Discussion}

The recommendations above are based on research on variations in the design of the PLC groups and the structure of the PBL problems. This section includesdiscussion of some of the key lessons learned and the variations that may make PBL an effective design for teacher PD in a variety of contexts.

One of the most important findings is that the PLC groups can be very effective in influencing teacher practice, but the changes are more likely if the members have a sense of belonging in the group. Salinas (2005) refers to this as a sense of "presence," the feeling that the group is sharing not a physical place but a common goal. To promote the sense of presence, planners worked with each group in the summer workshop to discuss goals and guidelines for discussion. Making the guidelines explicit helps members focus on teaching practice rather than talking about the teacher as the cause of a problem. For groups in which members felt like equal members, they quickly internalized the guidelines and became nearly self-facilitating. An experiment with one group suggested that teachers with experience in the PLC format and with the PBL framework are capable of functioning as a group without an external facilitator.

Other experiments found that PLCs that met in a virtual environment could be just as effective as those who met face-to-face. The virtual PLC groups (McConnell, Parker, Eberhardt, Koehler, \& Lundeberg 2013) met via webcams using a videoconference application that permits screen sharing, video, audio, and conference recording. The virtual groups were created to address the challenge of convening a group when teachers cannot easily meet face-to-face because of distance or difficulties in traveling to a meeting. Teachers who had a natural connection because of subjects and grades taught were located at distances that made a faceto-face meeting each month impractical. The groups, consisting mostly of teachers with prior experience in a face-to-face PLC, reported the same "sense of presence" as the in-person groups.

The research also suggests that giving teachers the task of selecting the focus of the PLC's inquiry is extremely important. This is a feature not of PBL, but of collaborative teacher inquiry into practice. PLCs are a very popular format for in-school PD right now in the United States. But administrators have chosen their own definition of a PLC to mean any group of teachers who meet for "PD." In many cases, the focus of the group's research and discussion is assigned by teachers who meet for "PD." In many cases, the focus of the group's research and discussion is assigned by a building or district administrator. A popular use of so-called "PLCs" is to create groups to identify trends and problems in standardized test scores or to review a problem identified by administrators as an area of need. While groups like these are necessary in some cases, they do not give teachers a sense of autonomy or professional respect (Talbert 2010). We found that groups who are 
assigned a task devote less effort to their tasks between meetings. More importantly, the changes in their practice are far more superficial and short-lived when the topics are assigned by others.

In order to make lasting changes in practice, $\mathrm{PD}$ planners need to honor the professionalism of participants by structuring the groups in ways that let teachers turn their attention to issues, problems and topics they find important and relevant. This recommendation can inform the make-up of groups to ensure that members of a group share a common goal. This finding aligns well with the goal of democratizing education and in this case, teacher education - that is so prevalent in the research about transformative education.

Another important finding is the role of peer-topeer accountability in motivating teachers to persist in their PD efforts. Data supporting this finding came from surveys and interviews with participants after the yearlong program. One of the themes that emerged in these sources of data is that teachers felt it was important to complete the tasks they were assigned by the group because of the shared leadership within the PLC group. The shared leadership was created by avoiding having a "group leader" who ran meetings. The facilitator served as a resource person and an aide in recording ideas. While the facilitator helped monitor time and redirect the group if discussion veered off topic, the leadership of the meetings was given to whichever teacher was sharing his or her own problem and evidence - the one referred to above as the problem's "owner."

A recurring comment from teachers each year was they felt "accountable to the group" each month. This was identified as a factor that helped encourage completion of tasks even when they considered avoiding the work they were doing for the PLC. Most teachers said this was true in a month when they presented their work, but that they also felt a sense of purpose when helping their colleague analyze their videos and review student work. One teacher wrote that she felt she "would be letting my group down" if she didn't bring resources to help others with their PBL problems.

\section{Conclusions}

Problem-Based Learning has been shown to be an effective structure for teacher professional development. When teachers use a systematic analytical approach to problems of pedagogy, they can more easily base their clinical decisions on evidence. PBL offers a structure that draws evidence both from research literature and from teacher-led inquiry in the classroom. Both of these are powerful sources of ideas that lead to long-term learning and changes in practice.

PBL, when used as described above, is adaptable to nearly any context. Teachers from different countries can use the PBL framework as a structure for PLCs to conduct their work. The culture of the PLC, because it is led by its members, will naturally fit the school community in which it is formed, and can focus on the specific needs of that group of teachers. The PLCs can address whatever problems are prevalent in their own community or school, whether it be related to effective education, meeting the social needs of a diverse and changing group of students, or create a school that is more responsive to the needs of the students and community it serves.

But for the purposes of our current discussion, PBL also represents a tool that is well adapted for creating a transformative learning environment. If we want teachers to make the kind of deep changes in consciousness, they need to be empowered to make the changes where and how they find them to be most appropriate. Democratizing schools often means allowing learners to take leadership roles and make important choices.

Teacher professional development should be viewed through the same lens - teachers are the learners. If we hope to democratize their professional learning, we must move away from the one-size-fits-all PD programs selected and designed by administrators. PBL serves as a process for turning over the control of much of the professional learning to the professionals and focus on change that will be sustainable while meeting the real needs of the community.

In order to bring about a shift toward this more teacher-centered approach to teacher professional development, we suggest a need to train teachers, administrators and PD leaders in the PBL process and the structure of effective Professional Learning Communities. With adequate training, those stakeholders will be more likely to plan time for the PLCs to meet, and more capable of creating and supporting effective and reflective teacher PLCs.

It is our hope that Problem-Based Learning for Responsive and Transformative Teacher Professional Development will serve as a resource that PD planners around the world can use to help them design, facilitate and implement such teacher centered professional learning experiences. 


\section{References}

Barrows, H. S. 1980. Problem-based learning: An approach to medical education. New York: Springer.

Carnegie Corporation of New York (CCNY). (2001). Teachers for a New Era: A national initiative to improve the quality of teaching. New York: Carnegie Corporation of New York.

Council for the Accreditation of Educator Preparation. (2013). CAEP accreditation standards.

Hord, S. M. (1997). Professional learning communities: Communities of continuous inquiry and improvement. Washington, D.C. Office of Education Research and Improvement.

Hung, W., D. H. Jonassen, and R. Liu. (2008). Problembased learning. In Handbook of research on educational communications and technology, 3rd ed., eds. J. M. Spector, M. D. Merrill, J. van Merriënboer, and M. P. Driscoll, 485-506. New York: Routledge.

McConnell, T. J., Parker, J. M., \& Eberhardt, J. (2013). Problem-based learning as an effective strategy for science teacher professional development. The Clearing House 86(6), 216-223.

McConnell, T. J., J. M. Parker, J. Eberhardt, M. J. Koehler, and M. A. Lundeberg. (2013). Virtual professional learning communities: Teachers' perceptions of virtual versus face-to-face professional development. Journal of Science Education and Technology, 22 (3), 267-277.

McConnell, T. J., Parker, J. M., \& Eberhardt, J. (2016). Problem-Based Learning in the Life Science Classroom, K-12. Alexandria, VA: NSTA Press.
McConnell, T. J., Parker, J. M., \& Eberhardt, J. (2017). Problem-Based Learning in the Earth-Space Science Classroom, K-12. Alexandria, VA: NSTA Press.

McConnell, T. J., Parker, J. M., \& Eberhardt, J. (2018). Problem-Based Learning in the Physical Science Classroom, $K-12$. Alexandria, VA: NSTA Press.

McConnell, T. J., Parker, J. M., \& Eberhardt, J. (In Preparation). Problem-Based Learning for Responsive and Transformative Teacher Professional Development. Alexandria, VA: NSTA Press.

Salinas E. 2005. Effects of communication mode on social presence, and performance in collaborative virtual environments. Presence 14(4):434-449.

Talbert, J. E. (2010). Professional learning communities at the crossroads: How systems hinder or engender change. In Second international handbook of educational change (pp. 555-571). Springer, Dordrecht.

Yaron, L. (2017). The five Ws of quality professional development. Education Week Teacher, May 9, 2017.

Zimpher, N. L. et al. (2010). Transforming teacher education through clinical practice: A national strategy to prepare effective teachers. Washington, D.C: National Council for Accreditation of Teacher Education.



